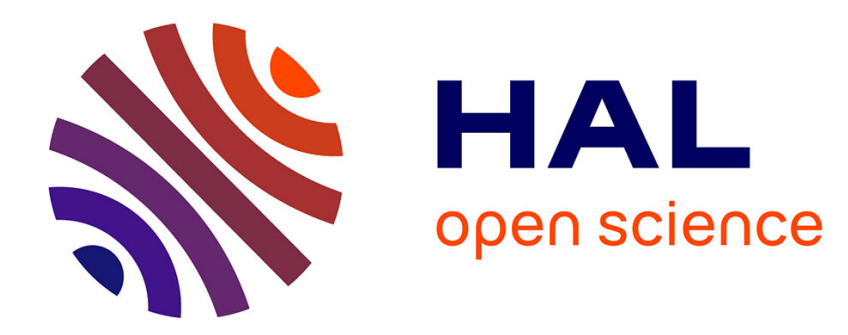

\title{
On the consistency of the Z-score to measure the bank risk
}

Ion Lapteacru

\section{To cite this version:}

Ion Lapteacru. On the consistency of the Z-score to measure the bank risk. 2016. hal-01301846

\section{HAL Id: hal-01301846 \\ https://hal.science/hal-01301846}

Preprint submitted on 13 Apr 2016

HAL is a multi-disciplinary open access archive for the deposit and dissemination of scientific research documents, whether they are published or not. The documents may come from teaching and research institutions in France or abroad, or from public or private research centers.
L'archive ouverte pluridisciplinaire HAL, est destinée au dépôt et à la diffusion de documents scientifiques de niveau recherche, publiés ou non, émanant des établissements d'enseignement et de recherche français ou étrangers, des laboratoires publics ou privés. 


\title{
lareflWorking Paper

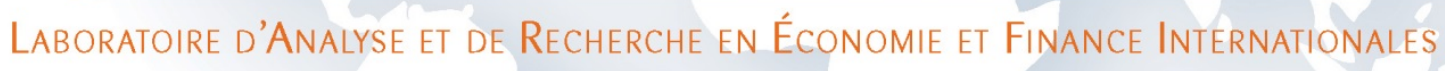 \\ On the consistency of the Z-score to measure the bank risk
}

\author{
Ion Lapteacru
}

\section{LAREFI Working Paper N²016-05}

http://lare-efi.u-bordeaux4.fr

\author{
LAREFI \\ Université de Bordeaux \\ Bâtiment Recherche Economie $-1^{\text {er }}$ étage \\ Avenue Léon Duguit - 33608 Pessac
}




\section{AUTHORS}

Ion Lapteacru, Larefi, Université de Bordeaux

\section{NOTICES}

LAREFI Working Papers contain preliminary material and research results. They have been peer reviewed. They are circulated in order to stimulate discussion and critical comment; any opinions expressed are only those of the author(s).

Copyright LAREFI. All rights reserved. Sections of this material may be reproduced for personal and not-forprofit use without the express written permission of but with acknowledgment to LAREFI. To reproduce the material contained herein for profit or commercial use requires express written permission. To obtain permission, contact LAREFI at cyril.mesmer@u-bordeaux.fr. 


\begin{abstract}
This paper raises questions about the consistency of the Z-score, which is the most applied accounting-based measure of bank risk. In spite of its advantage, namely the concept of risk on which it relies, the traditional formula is precisely inconsistent with its own concept. The Z-score is deduced from the probability that bank's losses exceed its capital, but under the very unrealistic assumption of normally distributed returns on assets. Consequently, we show that the traditional Z-score fails to consider correctly the distribution of banks' returns. To make the Z-score consistent and preserve its original concept of risk, we propose more flexible distribution functions. Between skew normal and stable distributions, we prove that the latter fits the best the distribution of banks' returns and therefore provides more reliable results for the Z-score. An application on the experience of the Central and Eastern European banks confirms this theoretical prove.
\end{abstract}

\title{
JEL classification: G21
}

Keywords: Z-score; Bank risk; Central and Eastern European economies. 


\section{Introduction}

A major challenge in the banking empirical literature is to conceive good measures of bank risk, especially based on accounting data. This issue is of a particular importance and interest: many banks are not listed, especially in emerging and developing countries, and there is no a consistent measure to gauge their risk. Some authors apply ratios of loan loss provisions and of impaired loans to total loans as measures of bank risk, others consider them as asset quality indicators. Indeed, it is not clear what the concept of risk behind these ratios is and to what extent the worsening of the bank's asset quality will engender its default. Standard deviations of Returns on Assets $(R O A)$ and of Returns on Equities ( $R O E)$ are also considered. However, with these measures, a bank is considered risky if it engages in activities that generate returns that are either higher or lower than the average return, which seems to be contradictory.

The Z-score is the only account-based risk measure that is founded on the risk concept and is also the most applied in the banking literature. Computed as the ratio of a bank's leverage (capital on assets) and the mean of its $R O A$ on the volatility of its $R O A$, this risk measure has been conceived from the concept of a bank's probability of default (Boyd and Graham, 1986; Hannan and Hanweck, 1988; Boyd and Runkle, 1993; Boyd et al., 1993). It is often applied either to measure the banking system stability (Lee and Hsieh, 2014) or the individual probability of default of banks (Laeven and Levine, 2009; Fiordelisi and Salvatore Mare, 2014; Williams, 2014).

However, this latter feature is a misinterpretation of the Z-score, because it can reflect the inverse probability of insolvency of a bank only if the returns on assets, as a random variable, are normally distributed. Its authors have warned against this important constraint (for instance, Boyd and Graham, 1986 p. 5; Boyd and Runkle, 1993 p. 53) and have proposed to apply the convergence properties of the $R O A$ random variable, through the Bienaymé- 
Tchebycheff inequality. The great strength of the Z-score is its foundation on the risk concept, which completely vanishes if normal distribution assumption is not respected. As we will show, the ROA distribution is, in reality, rather skewed and has an excess of kurtosis, and therefore its original definition and formula do not more express the inverse probability of default. Moreover, with the Bienaymé-Tchebycheff inequality the value of the probability of default approaches to its maximum value only with the increase in the sample size. But, with a sample of few years ${ }^{1}$, the probability of default can be, in reality, far from its upper level, which, in consequence, makes the Z-score inconsistent to measure the bank risk.

In this paper, we discuss the shortcomings of this most applied bank risk measure in the banking empirical literature and show why different proposals, as, for example, the Bienaymé-Tchebycheff inequality or the taking of the natural logarithm of the Z-score suggested by Laeven and Levine (2009), do not eliminate the problems they might face. The most important constraint with which the computation of the Z-score is confronted is the statistical distribution of $R O A$. Thus, in order to examine how its misspecification, with an implicit hypothesis of a normal distribution, leads to inconsistent estimates, we apply three different distributions: stable distribution, skew normal distribution and normal distribution. The first distribution is the most flexible and allows the best fit of banks' $R O A$ data. It takes into consideration both the skewness of data, a major shortcoming mentioned many times in the banking literature, and the kurtosis and sharpness of data. The skew normal distribution is the modified version of normal distribution, whose cumulative function is constructed with the Owen (1956) function. Its only advantage is to account for the asymmetry of $R O A$ distribution, which is not the case of the normal distribution. The latter is considered precisely to show its inconsistency to fit correctly $R O A$ data.

First, we check how each of our distributions fits simulated data with different skewness

\footnotetext{
${ }^{1}$ Bankscope Fitch IBCA, which is the most used bank database, provides annual data only for the last sixteen years.
} 
and sharpness parameters. Unsurprisingly, the stable distribution fits the best these data and the normal distribution the worst. Consequently, our (in)consistency tests based on Monte Carlo simulations prove that, for skewed and/or sharp $R O A$ distributions, the application of the normal distribution and traditional approach, but also the logarithmic transformation do not reduce the skewness and also fails to provide appropriate results.

Second, we make distribution fit tests for $R O A$ of Central and Eastern European banks over the period 1995-2013. Our choice of countries and period is supported by many troubles these banks faced: entry of foreign banks on these markets with new products and services, and better experience and knowledge, bank crisis events of nineties and the actual crisis, and tightening of banking regulatory environment. All of them shaped $R O A$ data of these banks very differently with respect to a normal distribution. Moreover, for such banking institutions, which for the most are not listed, a consistent accounting-based measure of risk is the only solution for researchers to assess their (in)solvency.

Finally, this paper makes a methodological contribution to the literature on bank risk. No work, to the best of our knowledge, has taken into account the skeweness and the kurtosis of $R O A$ data. Some endeavours were undertaken with the natural logarithm of the Z-score, instead of the Z-score itself (Laeven and Levine, 2009), but they are invalidated by our tests and findings. Beyond these remarks about the Z-score, our work hopefully contributes to reflections on accounting-based measures of bank risk.

The next section reviews the related literature and mentions the principal shortcomings of applied Z-score measures. Section 3 makes a technical review of shortcomings of the traditional approach to measure the Z-score. Section 4 explains the stable and skew normal distributions and presents consistency tests of these approaches with traditional estimates of the Z-score. Section 5 evaluates this risk measure for a panel of Central and Eastern European banks, and Section 6 summarises our main findings and concludes. 


\section{Z-score: how it is applied in the banking literature?}

In the banking literature, researchers apply very different versions of the Z-score. Some of them use the traditional formula, i.e. Zscore $=\frac{\operatorname{mean}(R O A)+C A R}{\operatorname{std}(R O A)}$, where $R O A$ and $C A R$ are returns on assets and capital on assets ratios, respectively, and mean $(R O A)$ and $\operatorname{sigma}(R O A)$ are empirical estimates of mean and of standard deviation of $R O A$, respectively. Others apply kinds of modifications (see table 1), which aim either to overcome some shortcomings inherent to this accounting-based risk measure or to make this measure more changing.

Table 1 proposes a summary of empirical studies in the banking literature that apply the Z-score as a bank risk measure. It reviews only revealing examples about the main approaches in estimating the Z-score. As explained below, the traditional approach is the closest to the concept of this risk measure. It considers $R O A$ as a random variable, distribution of which is taken in the determination of the Z-score using the formula of the probability of default. According to its founders, Hannan and Hanweck (1988), Boyd and Runkle, (1993), and Boyd et al. (1993), the default event occurs when current losses exceed capital. Normalising by a bank's assets, the probability of default is thus $\operatorname{Pr}[R O A \leq-C A R]$. Taking empirical mean and empirical standard deviation of $R O A$ random variable on entire period sample, the traditional method allows the determination of the Z-score but only with the assumption of a normally distributed ROA (Demirgüç-Kunt and Huizinga, 2010).

However, in practice, in most of cases $R O A$ distributions are skewed and have an excess of kurtosis. There are much of $R O A$ that are lower than their average level and the distribution is left-skewed for countries whose banking industries encounter some trouble and crisis events. Conversely, if the banking industries are coming out of such events, there are much of $R O A$ that are higher than their average level and the distribution is right-skewed. Moreover, the extreme values of $R O A$ are more frequent than those described by a normal distribution. In order to mitigate the effects of these shortcomings, Laeven and Levine (2009) and Demirgüç- 
Kunt et al. (2008), for instance, propose to use natural logarithm of the Z-score and of one plus Z-score, respectively. The latter is only to be able to consider the negative values of this bank risk measure. As explained and shown below, our tests however refute the improvement supposed to be provided by the logarithmic transformation.

All other versions of the Z-score depart even more from the original concept. Estimating the empirical mean and empirical standard deviation of $R O A$ only on a part of the time sample (2, 3, 4 or 5 years) and rolling these calculus on this time window on the rest of the sample make the Z-score more sensitive and therefore more fluctuating (Anginer et al., 2014; Williams, 2014; among others). Authors consider probably that in this way they can better capture instantaneous changes in a bank's situation. Nevertheless, assimilating the expected value and the theoretical standard deviation of the $R O A$ distribution to their empirical estimates only on a part of the time window, this approach avoids even more the concept of risk. Other authors consider even a more sensitive Z-score, by estimating yearly risk measure with quarterly average and standard deviation of $R O A$ and quarterly average of $C O A$ (Anolli et al., 2014; De Haan and Poghosyan, 2012). It is the same as to take all these values in level with yearly frequency. Overall, this makes no more sense with the concept of Z-score, where the distribution of the $R O A$ random variable must be taken into account. The sense of the Zscore completely disappears when, instead of the $R O A$, some authors use $R O E$, i.e. returns on equity, as random variable (De Haan and Poghosyan, 2012; Lee and Hsieh, 2014).

Many papers in banking literature treat the risk of banks using a Z-score with $R O A$ in level instead of average in the numerator, and standard deviation on rolling window (Lee and Hsieh, 2014; Chortareas et al., 2012) or on entire time sample (Niu, 2012) in the denominator. As explained above, this approach does not more consider the distribution of the $R O A$ random variable, which is at the heart of the concept of this bank risk measure. The probability of default, $\operatorname{Pr}[R O A \leq-C A R]$, has no more sense since it does not more participate to the 
deduction of the Z-score formula, especially when some authors apply a standard deviation across banks (Fiordelisi and Mare, 2014). Such measures cannot be considered as proxy for bank risk because they do not express the bank (in)solvency.

To summarise, one may mention the following main shortcomings of different approaches to measure the Z-score. First, the closest method to this concept of bank risk, which is the traditional approach, is strongly related to the normal distribution hypothesis of the $R O A$ random variable. However, in practice, the latter is often skewed and has an excess of kurtosis, and some attempts to mitigate this shortcoming fail to provide appropriate results. Second, all versions of the Z-score that make it more sensitive consist in the determination of the empirical mean and empirical standard deviation of the $R O A$ only on a certain part of the time sample, which makes these estimations different from the expected value and the theoretical standard deviation of the ROA. Third, the use of this random variable in level instead of its average value takes away any feature of randomness and therefore any feature of the $R O A$ distribution and of the probability of default from the concept of bank risk. Finally, values of the Z-score higher than 4 bring to naught any attempt to explain them through the probability of default and under the assumption of normal distribution, as is the case for all cited papers. For example, the Z-score equals to 14 corresponds to the probability of default equals to $8.8 \square 10^{-45}$, and the value of 22.6 is in line with the probability of default of $2.6 \square 10^{-113}$. How to interpret these results? More precisely, how to explain such probabilities of default, whose values are very close to zero? Does the increase of the probability of default by $10^{68}$ times, till $8.8 \square 10^{-45}$, signify that the bank risk rises as much?

\section{Inconsistency of the traditional Z-score}

Among all these different versions of the Z-score, we will explore the consistency of the traditional approach since it is the closest to the concept of bank risk. This approach, i.e. 
$Z=\frac{C A R+E(R O A)}{\sigma(R O A)}$, defines the default event when current losses exceed capital and the probability of default is, in consequence, $\operatorname{Pr}[-\Pi>C]$, where $\Pi$ is the bank's profit and $C$ its capital. Normalising by the bank’s size, expressed by its assets' level $A$, the probability of default becomes $\operatorname{Pr}[\Pi \leq-C]=\operatorname{Pr}[R O A \leq-C A R]$, where $R O A=\Pi / A$ is the returns on assets ratio and $C A R=C / A$ is the capital on assets ratio. The bank's performance, expressed by its profit or returns on assets, is a random event and is reflected by its distribution. Within the traditional approach, according to Boyd and Runkle, (1993), Hannan and Hanweck (1988), and Boyd et al. (1993), one assumes that ROA is normally distributed and the probability of default is therefore given by

$$
\operatorname{Pr}[R O A \leq-C A R]=\operatorname{Pr}\left[\frac{R O A-E(R O A)}{\sigma(R O A)} \leq-\frac{C A R+E(R O A)}{\sigma(R O A)}\right]=N(-\mathrm{Z})=1-N(\mathrm{Z}),
$$

where $E(R O A)$ is the expected value of $R O A, \sigma(R O A)$ its standard deviation and $N($.$) is the$ normal cumulative distribution function.

Graphical presentation of the Z-score with the normal distribution assumption of the ROA clearly shows that this risk measure cannot obtain values higher than 4, otherwise, they cannot be explained because the probability of default is very close to zero (see Figure 1). However, with more left-skewed probability density function higher values of the Z-score have more sense, because the probability of default obtains values different from zero.

Thus, the assumption of normally distributed $R O A$ allows the derivation of a simple and easily calculable, but also inconsistent, formula for the Z-score. Indeed, the distribution of the $R O A$ is, in reality, asymmetric (skewed) and has an excess of kurtosis. According to Boyd and Runkle, (1993), Hannan and Hanweck (1988), and Boyd et al. (1993), even if the ROA is not normally distributed, using the Bienaymé-Tchebycheff inequality, the Z-score remains still a good measure of bank risk and becomes the inverse measure of the upper bound of the probability of default: 
$\operatorname{Pr}[R O A \leq-C A R]=\operatorname{Pr}[R O A-E(R O A) \leq-(C A R+E(R O A))] \leq \frac{\sigma^{2}(R O A)}{2(C A R+E(R O A))^{2}}=\frac{1}{2 Z^{2}}$

But this is still valid only for a symmetric distribution of the $R O A$. Otherwise, one might apply Cantelli's inequality that lead to the following expression for the probability of default:

$$
\operatorname{Pr}[R O A \leq-C A R] \begin{cases}\leq \frac{1}{1+Z^{2}}, & \text { if } C A R+E(R O A)>0 \\ \geq \frac{Z^{2}}{1+Z^{2}}, & \text { if } C A R+E(R O A)<0\end{cases}
$$

which changes the relationship between the Z-score and the probability of default: the increase in the $Z$-score reduces the upper limit and raises the lower limit, and vice versa. Anyway, having an interval for the probability of default provides no information about its true value, or at least its mean value. For this reason, the Z-score, without normal distribution assumption, cannot ensure the comparability of bank risk data. Moreover, the convergence of the true value of the probability of default to its upper limit will depend on the properties of the statistical law of the $R O A$ random variable.

The only way to compute consistently the Z-score is therefore by using its original concept of probability of default, where the probability of default is the cumulative distribution function at the minus Z-score. Thus, its correctness depends on the goodness of fit of the applied distribution to the left tail of the $R O A$ distribution. Generating some $R O A$ samples with location parameter 2.5 and scale parameter 1.5, we show in Figure 2 that normal distribution fits, generally, not very well the smooth kernel distribution of generated samples (we explain later how it is constructed). The fit is worst for high sharpened and skewed ROA distributions $(|S|>0.5$, namely the cases 1-4 and 6). A better fit provides the skew normal distribution (we explain later how it is constructed). As an asymmetric version of the normal distribution, it takes into account the skewness of distributions, which is shown by the cases 1 and 3 of Figure 2. However, as stated later, it is not the best way to address the problem of excess of kurtosis ( $\mathrm{K}>3$ ), and cannot therefore provide an excellent goodness of fit. 
Among those presented in Figure 2, the stable distribution is the best. As for previous one, the details are presented in next section. Its four parameters - location parameter, scale parameter, skewness parameter $(\alpha)$ and stability parameter $(\beta)$ - make it very flexible and allow a perfect shape, which fits very well the contour of the smooth kernel distribution of randomly generated $R O A$. The latter parameter describes the sharpness of the distribution: lower it is, sharper is the distribution. It takes positive values with highest equal to 2 for a normal distribution. In the next section, we examine thoroughly the properties of all these distributions and make consistency tests for Z-score measures estimated using the concept of probability of default. However, we can already assign a certain performance of the stable distribution in comparison with the other two.

\section{The consideration of the skewness and of the kurtosis for the $R O A$ distribution and consistency tests with the traditional Z-score}

As main shortcoming of the traditional Z-score is the assumption of the normal distribution for the $R O A$ variable, we propose in this section other methods to compute this accounting-based risk measure. Then, we submit them to consistency tests, using Monte Carlo simulations.

\subsection{Some proposals to consider the skewness and the kurtosis}

The most simple and direct way to mitigate the above-mentioned shortcomings of the normal distribution, at least some of them, is to adjust this distribution. The first proposal is therefore to use the skew normal distribution, which adds the skewness to a normal distribution shape by applying the Owen (1956) function

$$
T(x ; \mu, \sigma, \alpha)=\frac{1}{2 \pi} \int_{0}^{\alpha} \frac{\exp \left[-\frac{1}{2}\left(\frac{x-\mu}{\sigma}\right)^{2}\left(1+t^{2}\right)\right]}{1+t^{2}} \mathrm{~d} t .
$$


Consequently, the cumulative distribution function is

$$
F_{S k N D}(x ; \mu, \sigma, \alpha)=N(x ; \mu, \sigma)-2 T(x ; \mu, \sigma, \alpha),
$$

where $N(x ; \mu, \sigma)$ is normal cumulative distribution function for a distribution with scale parameter $\sigma$ and location parameter $\mu$. The skewness parameter $\alpha$ allows the consideration of the asymmetry. For $\alpha=0, F_{S k N D}(x ; \mu, \sigma, 0)=N(x ; \mu, \sigma)$ and the distribution is symmetric. Otherwise, if $\alpha<0$, then $T(x ; \mu, \sigma, \alpha)<0$ and $F_{S k N D}(x ; \mu, \sigma, \alpha)>N(x ; \mu, \sigma)$, and the distribution is left-skewed. For $\alpha>0$, we obtain $T(x ; \mu, \sigma, \alpha)>0, F_{S k N D}(x ; \mu, \sigma, \alpha)<$ $N(x ; \mu, \sigma)$ and a right-skewed distribution.

The skewness of this distribution, which is $\sqrt{2}(4-\pi) \alpha^{3} /\left(\pi+(\pi-2) \alpha^{2}\right)^{3 / 2}$, takes values ranging from -0.995 (for $\alpha \rightarrow-\infty$ ) to 0.995 (for $\alpha \rightarrow+\infty$ ). Its kurtosis, which is computed by the following formula $3+8(\pi-3) \alpha^{4} /\left(\pi+(\pi-2) \alpha^{2}\right)^{2}$, is equal to 3 for $\alpha=0$ and takes the maximum value of 3.87 for $\alpha \rightarrow \pm \infty$, and the skew normal distribution has therefore an excess of kurtosis. Even though the ROA distribution in banking is rather characterised by an excess of kurtosis, the skew normal distribution function cannot take into account few of cases where the kurtosis could be lower than 3 and many of cases where the kurtosis exceeds 3.87 (see Figure 2).

The second proposal is the stable distribution, which is very flexible and allows the consideration of most of distribution cases. The difficulty is that it does not have a general analytical expression for probability distribution and cumulative distribution functions. A random variable is called stable if its characteristic function can be written as $\varphi(t ; \beta, \alpha, \mu, \sigma)=\exp \left[i t \mu-|\sigma t|^{\beta}(1-i \alpha \operatorname{sgn}(t) \Phi)\right]$, where

$\Phi=\left\{\begin{array}{cl}\tan \left(\frac{\pi \beta}{2}\right), & \text { if } \beta \neq 1 \\ -\frac{2}{\pi} \log |t|, & \text { if } \beta=1,\end{array}\right.$

and $0<\beta \leq 2$ represents the stability index, $-1 \leq \alpha \leq 1$ the skewness parameter, $\mu \in \mathbb{R}$ the 
location parameter and $\sigma>0$ is the scale parameter. The huge advantage of the stable distribution is its quasi-general form that comprises some well-known distributions. For $\beta=2$, it is transformed to a normal distribution with variance $2 \sigma^{2}$ and expectation $\mu$, and therefore the skewness parameter $\alpha$ has no effect. For $\beta=1$ and $\alpha=0$, one obtains Cauchy distribution and for $\beta=1 / 2$ and $\alpha=1$ Lévy distribution, both distributions with scale parameter $\sigma$ and location parameter $\mu$.

The main advantage of the stable distribution is its flexibility and therefore a better coverage of the ROA data. We further test which of these three distributions - stable, skew normal and normal distributions - fits the best randomly generated data with different shape.

\subsection{Consistency tests of the traditional Z-score}

In order to make distribution fit tests and afterwards the consistency tests of the traditional Z-score, we simulate twenty values of $R O A$ for each of fifty banks and nine cases, which are the same as in Figure 2. The twenty values correspond to maximum number of years considered in the banking literature and nine cases are three cases with different sharpness of the probability density function each of them with three different skewnesses (left skewed, symmetric and right skewed distributions). More precisely, the nine randomly generated series are with the same location, $\mu=2.5$, and scale, $\sigma=1.5$, parameters, and with three different sharpness or stability index: $\beta=0.25, \beta=1$ and $\beta=1.75$, each of them with three different skewness parameters, $\alpha=-0.75, \alpha=0$ and $\alpha=0.75$.

First, we determine the distribution parameters that fit the best the randomly generated $R O A$ values, and, afterwards, we make distribution fit tests. While the parameters of skew normal and normal distributions can be estimated using analytical methods, as Maximum Likelihood estimator or estimator of Moments, those of the stable distribution lack such methods for their determination because this distribution has no analytical probability density 
function, except for some parameter values. This is why we apply the same empirical computational method for all three distributions, which consists to find the parameters that draw the probability distribution function the nearest to the smooth kernel distribution. The latter has a probability density function for a value $x$ that is given by a linearly interpolated version of $\frac{1}{n h} \sum_{i=1}^{n} k\left(\frac{x-x_{i}}{h}\right)$ for a smoothing kernel $k(x)$ and bandwidth parameter $h$, where $n$ is the number of observations of the sample composed by $x_{i}$ values. We consider a Gaussian kernel specification, whose the bandwidth selection method is Silverman's (1998) rule. The optimal choice provided by this rule is $h=\left(4 \hat{\sigma}^{5} / 3 n\right)^{\frac{1}{5}}$, where $\hat{\sigma}$ is the standard deviation of the sample.

Second, we make three distribution fit tests, i.e. Anderson-Darling test, Cramer-vonMises test, and Kolmogorov-Smirnov test. We test whether the randomly generated samples with twenty values of $R O A$ are drawn from these three probability distribution functions. The Anderson-Darling and Cramer-von-Mises statistics belong to the class of quadratic empirical distribution function statistics. If the hypothesised distribution is $F$ and empirical cumulative distribution function is $F_{n}$, then this type of statistics measures the distance between these two cumulative distribution functions by $n \int_{-\infty}^{+\infty}\left(F_{n}(x)-F(x)\right)^{2} w(x) d F(x)$, where $w(x)$ is a weighting function. When the weighting function is $w(x)=1$, one obtains the Cramer-vonMises statistic, and when it is $w(x)=[F(x)(1-F(x))]^{-1}$, it is the Anderson-Darling statistic. The Kolmogorov-Smirnov statistic is equivalent to that of Cramer-von-Mises with the difference that it uses the absolute value, i.e. $\left|F_{n}(x)-F(x)\right|$, instead of squared value. Thus, compared to the Cramer-von-Mises and Kolmogorov-Smirnov distances, the AndersonDarling distance places more weight on observations in the tails of the distribution. Regarding the original concept of the Z-score whose minus value allows the determination of the probability of default, we will therefore focus on this last test. Our choice is also motivated by 
a worse distribution fit on tails by the normal and skew normal probability density functions (see Figures 1 and 2).

The estimated parameters for all three distributions and all nine cases are presented in table 2. When randomly simulated $R O A$ samples are skewed, both the stable and skew normal distributions capture this configuration with $\alpha<0$ for left-skewed samples (cases 1, 4, and 7) and with $\alpha>0$ for right-skewed samples (cases 3, 6, and 9).

As for distribution fit tests presented in table 3, they confirm our previous assumptions. The stable distribution fits the best randomly distributed values, especially those with highest sharpness of the probability density function. The first three cases, with sharpness parameter $\beta=0.25$, show that among fifty Anderson-Darling tests more than forty reject the hypothesis that skew normal and normal distributions fit randomly generated samples with twenty values. And this test rejects this hypothesis only three or two times (cases 2 or 3, respectively) or not at all for stable distribution. Even though this difference is less overwhelming with Kolmogorov-Smirnov and Cramer-von-Mises statistics, more than half of tests are still rejected with the Kolmogorov-Smirnov statistic for the left-skewed distribution (case 1).

Consequently, the distribution fit tests on strongly sharpened distributions support the idea that the stable distribution fits the best $R O A$ data and is therefore the best distribution. With the reduction of the distribution's sharpness and with the increase of this parameter to $\beta=1.25$, its advantage diminishes. Even though the three statistics cannot reject for each of fifty samples the goodness of fit of the stable distribution, the rejection is present only approximately for ten samples for skew normal and normal distributions with AndersonDarling statistic, and for none of them with other two statistics. Once again, the stable distribution fits the best the tails of a distribution and therefore corresponds better to the concept of the Z-score. Finally, with a shape closer to that of a normal distribution, i.e. with $\beta=1.75$, all three distributions fit well the randomly generated data (cases 7,8 , and 9). All of 
these tests correspond to graphics depicted in Figure 2 and confirm that the normal distribution fails to cover many cases of banks' $R O A$ distribution. The stable distribution do better and can therefore be applied to keep the concept of risk in the Z-score computations.

We will now check the consistency of the traditional Z-score with methods based on stable, skew normal and normal distributions. For this, we follow the approach explained above according to which minus Z-score will be the point at which the $N($.$) function is equal$ to the probability of default computed with different cumulative distribution functions:

$$
\begin{aligned}
& \text { Zscore } 1=-N^{-1}\left(F_{S t D}\left(-C A R ; \beta, \alpha_{1}, \mu_{1}, \sigma_{1}\right)\right), \\
& \text { Zscore } 2=-N^{-1}\left(F_{S k N D}\left(-C A R ; \alpha_{2}, \mu_{2}, \sigma_{2}\right)\right), \\
& \text { Zscore3 }=-N^{-1}\left(N\left(-C A R ; \mu_{3}, \sigma_{3}\right)\right)=\frac{C A R+\mu_{3}}{\sigma_{3}},
\end{aligned}
$$

where $F_{S t D}($.$) and F_{S k N D}($.$) are stable and skew normal cumulative distribution functions,$ respectively. As the former does not have an analytical expression, we apply the characteristic function of the stable distribution (Eq. 2) to compute the Zscore1. We use equation (1) for the cumulative distribution function of the skew normal distribution to estimate the Zscore2. Finally, the traditional Z-score measure is computed as

$$
\text { Zscore } 4=\frac{C A R+\operatorname{mean}(R O A)}{\operatorname{sigma}(R O A)}
$$

where mean $(R O A)$ and $\operatorname{sigma}(R O A)$ are empirical estimates of mean and of standard deviation of $R O A$, respectively.

We conduct a Monte Carlo simulation to test the consistency of different Z-score measures. We take an expected value of $R O A$ of $2.5 \%, \mu=2.5$, and a standard deviation of $R O A$ of $1.5 \%, \sigma=1.5$, which are empirical levels observed over our sample of CEE banks. We thus generate 50 samples of years from stable distributions with such parameters and with different values of skew parameter $\alpha$ and of sharpness parameter $\beta$, and with values of $R O A$ ranging from $-20 \%$ to $20 \%$. For each value of $\beta$, which ranges from 0.25 to 2 with a step of 
0.25 , we make estimations with parameter $\alpha$ from -1 to 1 with a step of 0.2 . We thus randomly generate $R O A$ samples with 20 years based on these different stable distributions. To find the corresponding skew normal and normal distributions, for each of these samples we estimate the parameters of these distributions using the procedure explained above (point 4.2). These parameters must bring closer as possible the skew normal and normal distributions to the smooth kernel distribution using 10000 values of $R O A$ randomly generated by the stable distribution.

The Z-score and its natural logarithm are computed for a capital assets ratio, CAR, varying from 0 to $5 \%$ with a step of $0.25 \%$, i.e., with 21 values. For each value of $\alpha$ and $\beta$ parameters, we make the consistency test between, on the one hand, stable, skew normal, and normal distributions, and, on the other hand, the traditional approach. The tests are repeated for each value of $C A R$ for which we repeat the calculus 50 times, each of them with 50 samples of years. Thus, Figures 3-5 present the fraction of cases that do not reject the null hypothesis of consistency for the total number of cases, which is $1050=50 \square 21$. Thus, for each of these 1050 cases, we perform 50 estimates, and the consistency test is therefore realised for each value of $\alpha$ and $\beta$ parameters with $52500=50 \square 1050$ computations, and for each we estimate the parameters of the corresponding skew normal and normal distributions.

According to simulation results, both risk measures, i.e., the Z-score (eqs. 3, 4, 5 or 6) and its logarithm, reject the null hypothesis of consistency for highly skewed and highly sharpened $R O A$ distributions, at 5\% significance level. More precisely, for the sample of 20 years, only about $80 \%$ of cases do not reject the null hypothesis of equality between the risk measure computed with stable distribution function and the Z-score computed with traditional approach, but this is the case only for $\beta$ closer to 2 (Figure 3). The result is in the same vein as for the null hypothesis of equality between the risk measure computed with skew normal distribution function and the traditional approach (Figure 4), and between the Z-score 
estimated with normal distribution function and the traditional approach (Figure 5). This last outcome corresponds only for parameter $\alpha$ closer to 1 . Moreover, the logarithmic transformation does not improve the results of these simulations and therefore does not mitigate the skewness and kurtosis problems of $R O A$ distributions.

We can thus draw two useful conclusions. First, if $R O A$ distribution is skewed and/or has an excess of kurtosis, the application of the traditional approach provides inconsistent results. Second, the logarithmic transformation does not reduce the skewness and therefore fails to provide appropriate results. In addition, the traditional approach and the normal distribution assumption are not equal (Figure 5), probably because the empirical estimates of mean and of standard deviation of $R O A$ are not really good proxies for expected value and standard deviation of normal distribution. These are some of reasons why the traditional Z-score is inappropriate to measure the bank risk, based on the original concept of probability of default.

\section{Traditional and improved Z-scores: Evidence from Central and Eastern European}

\section{banks}

We now apply the three explored distribution functions in estimating the Z-score and compare these risk measures with the traditional Z-score in the case of Central and Eastern European banks. Many reasons guided us in the choice of these countries. First, at the beginning of the transition period, lax entry requirements led to the appearance of many new domestic private banks, some of which were of dubious quality or even fraudulent (Bonin et al, 1998). Even those that had real intentions to carry out profit- and development-oriented banking activities had no experience in monitoring and producing information about their investments (Bonin et al., 2015).

Second, given the risky nature of their activities and the troubles characterising these transition economies, in the mid-1990s, crises occurred in most CEE countries. Third, after 
these episodes and restructuring processes that followed, and as a result of new regulatory constraints, new experiences and bank practices, the risk-taking behaviour of these banks changed.

Finally, CEE banking markets are characterised with large foreign banks, which are essentially from Western Europe, and large state-owned banks, which, at the beginning of the transition, maintained banking relationships with their large, inefficient state-owned enterprises (Bonin et al., 2015). Moreover, as sectoral or regional banks, the public banks were a financial instrument of the political and social policies of successive governments (OECD, 1996, Bonin et al., 1998), which weakened these institutions and probably made them riskier. On the other hand, foreign banks in CEE countries, at the beginning, had exclusively the expertise, technology and know-how for credit screening and risk management, among other risk-reducing skills. All these reasons involve samples of banks' $R O A$ that might be skewed and might have an excess of kurtosis, i.e., samples that are not normally distributed.

Returns on assets, $R O A$, and capital on assets, $C A R$, data are extracted on an annual basis from Bankscope Fitch IBCA over 1995-2013 period. This period covers early transition restructuring processes, entry of foreign banks into these markets, and two banking crisis events: those of the 1990s and the recent financial crisis.

Our sample consists of 322 banks from ten CEE economies, including Bulgaria, the Czech Republic, Hungary, Estonia, Latvia, Lithuania, Poland, Romania, Slovakia and Slovenia. In order to assure the consistency of distribution fit tests and of estimated parameters, only banks with at least ten observations are considered. Our final bank sample contains 193 banks from these ten CEE countries.

We first make distribution fit tests, whose results are presented in table 4. As previously, the parameters of distributions are estimated empirically based on method explained in 
Section 4. These results indicate how many banks on entire bank sample do not conform to the estimated distributions according to their $R O A$ distribution's shape. They clearly show that the stable distribution fits the best the ROA data of CEE banks for all countries. As proved above with Monte Carlo simulations, its performance is revealed in the better consideration of tails. Only one bank from 23 for Bulgaria and one bank from 25 for Romania have ROA data over 1995-2013 period that are not well fitted by the estimated stable distribution at tails (Anderson-Darling test). For all other countries, the $R O A$ samples of all banks comply well with the estimated stable distribution.

As expected, the estimated skew normal and normal distributions fail to shape $R O A$ data for many banks of all CEE countries. For some countries, as Estonia, Latvia, Lithuania, Slovakia and Slovenia, the estimated normal distribution fails to comply well with $R O A$ data at tails, at least for the half of banks of the sample. This distribution is even rejected for one Polish bank with Cramer-von-Mises and Kolmogorov-Smirnov tests, too. Finally, excepting for Bulgaria and Hungary, the normal distribution fits the worst the $R O A$ data at tails.

This discrepancy of the goodness of fit is therefore passed on the results of the Z-score, which are presented in table 5. First, the level of Zscore1, estimated using the stable distribution (eq. 3), is always, and for all countries, lower than all other three Z-score measures, i.e. Zscore2, computed using the skew normal distribution (eq. 4), Zscore3, determined using the normal distribution (eq. 5), and Zscore4, which is the traditional Z-score measure (eq. 6). This corresponds to the critics evoked in section 2, according to which the Zscore cannot obtain high values because the probability of default is very close to zero (see Figures 1 and 2). How we can see, Zscore2, Zscore3 and Zscore4 are highly concerned with these critics and, on the contrary, Zscore1 is completely free of them.

Second, while Zscore1 varies maximum with 1.5 points (Bulgaria in 2000, Czech Republic in 1999, Latvia in 1998), Zscore2 and Zscore3 can change with more than 45 points 
and Zscore4 with more than 14 points (Latvia in 1996). As explained in section 2, values of 55 (Zscore2 and Zscore3 for Latvia in 1995) are senseless, as any other value that is higher than a level for which the probability of default cannot be considered different from zero.

Third, Zscore1 is also distinguishable by its trend. It shows, for example, the decrease in the Bulgarian banks' risk in 1997, 1999, 2001, 2003, in that of Czech banks in 1999, 2000, 2002, or in that of Latvian banking institutions in 1998 and 2004, whereas other three Z-score measures suggest the increase of these banks’ risk during the same periods. Likewise, the results show the inverse contradiction, as, for example, for Czech Republic in 1998 and 2004, for Latvia in 2001, for Hungary in 2000 and 2006, or for Romania in 2000, or no correlation at all between Zscore1 and other Z-score measures.

Finally, all Z-score measures consider the banking crises in CEE economies during the nineties, but somewhat differently. Zscore 1 shows, for example, that the bank risk decreases continuously after the Bulgarian banking crisis in 1995, which is not the case of the other three Z-score measures registering a huge increase of the risk in 1997. It is much the same case with Latvian and Slovenian banks in 1998. An inverse situation is also present. While Zscore1 describes a higher risk for Czech, Hungarian and Slovakian banks in 1998, Zscore2, Zscore3 and Zscore4 show, on the contrary, that these banks reduced their risk-taking.

\section{Conclusion}

It is very important to have a good accounting-based measure of bank risk, because many banks are not listed and marked-based measures cannot be applied. The Z-score is the most used but it undergoes many shortcomings, which undermine its main advantage that is the concept of probability of default. In this paper, we investigated the weaknesses of the traditional Z-score and, namely, the hypothesis of normal distribution of the banks' ROA. Some of its versions fail to overcome the problems inherent to normal distribution constraint, 
as the skewness and the excess of kurtosis, or erase the original concept of probability of default. Using Monte Carlo simulations, our test, clearly rejects the assumption that the logarithmic transformation, as a way to deal with the skewness, provides better results.

Because the normal distribution does not fit well the $R O A$ data, the tails are not correctly taken into account, and the probability of default and the Z-score are miscalculated. We propose to comply exactly with the concept of the probability of default and, at the same time, to overcome the shortcomings of the normal distribution. Instead of the latter, we therefore suggest considering the stable distribution, because it is the most flexible and fits the best different kinds of distributions.

Our empirical application on the experience of CEE banks confirms the theoretical advantages of the stable distribution. The Anderson-Darling test, which places more weight on observations in the tails, does not reject the hypothesis that the $R O A$ data of all banks comply well with the estimated stable distribution. For skew normal and normal distributions, this test is sometimes rejected for more than a half of banks. Estimations of Z-score, based on stable, skew normal and normal distributions, but also on the traditional approach, provide results in the same vein. With stable distribution, the Z-score obtains values that make sense, which is not always the case with the other two distributions because of the too high and thus meaningless values of this risk measure.

We thus emphasised the most important shortcomings of the most used accounting-based measure of banking risk in the banking empirical literature and proved them with different tests and estimations on CEE banks. Other limits may be raised, as the formulation of the default event, which is too restrictive and does not take into account other factors than bank losses in the determination of the probability of default. Nevertheless, any attempt to overcome them must to keep the original concept of risk. 


\section{Acknowledgements}

We wish to thank Laurent Weill for his constructive comments and helpful suggestions.

All remaining errors are ours. 


\section{References}

Anginer, D., Demirgüç-Kunt, A., Zhu, M., 2014. How does deposit insurance affect bank risk? Evidence from the recent Crisis. Journal of Banking and Finance 48, 312-321.

Anollia, M., Beccalli, E., Molyneux, Ph., 2014. Bank earnings forecasts, risk and the crisis. Journal of International Financial Markets, Institutions and Money 29, 309-335.

Bonin, J.P., Mizsei, K., Székely, I.P., Wachtel, P., 1998. Banking in Transition Economies: Developing Market Oriented Banking Sectors in Eastern Europe. Cheltenham, UK Northampton, Edward Elgar, MA, USA.

Bonin, J.P., Hasan, I., Wachtel, P., 2015. Banking in Transition Countries. In: The Oxford Handbook of Banking, Berger, Allen N., Molyneux, Philip, Wilson, John O.S., second edition. Oxford University Press, United Kingdom, 963-983.

Boyd, J.H., Runkle, D.E., 1993. Size and performance of banking firms. Journal of Monetary Economics 31, 47-67.

Boyd, J.H., Graham, S.L., Hewitt, S.R., 1993. Bank holding company mergers with nonbank financial firms: effects on the risk of failure. Journal of Banking and Finance 17, 43-63.

Chortareasa, G.E., Girardoneb, C., Ventouric, A., 2012. Bank supervision, regulation, and efficiency: Evidence from the European Union. Journal of Financial Stability 8, 292-302.

De Haan, J., Poghosyan, T., 2012. Bank size, market concentration, and bank earnings volatility in the US. Journal of International Financial Markets, Institutions and Money 22, $35-54$.

Demirgüç-Kunt, A., Detragiache, E., Tressel, T., 2008. Banking on the principles: Compliance with Basel Core Principles and bank soundness. Journal of Financial Intermediation 17, 511-542.

Demirgüç-Kunt, A., Huizinga, H., 2010. Bank activity and funding strategies: The impact on risk and returns. Journal of Financial Economics 98, 626-650. 
Fiordelisi, F., Salvatore Mare, D., 2014. Competition and financial stability in European cooperative banks. Journal of International Money and Finance 45, 1-16.

Hannan, T.H., Hanweck, G.A., 1988. Bank insolvency risk and the market for large certificates of deposit. Journal of Money, Credit and Banking 20, 203-211.

Laeven, L., Levine, R., 2009. Bank governance, regulation and risk taking. Journal of Financial Economics 93, 259-275.

Lee, C.-C., Hsieh, M.-F., 2014. Bank reforms, foreign ownership, and financial stability. Journal of International Money and Finance 40, 204-224.

Niu, J., 2012. An empirical analysis of the relation between bank charter value and risk taking. The Quarterly Review of Economics and Finance 52, 298-304.

Organisation for Economic Co-operation and Development (OECD), 1996. Romanian Restructuring of the Banking Sector. OECD, Paris.

Owen, D.B., 1956. Tables for computing bivariate normal probabilities. Annals of Mathematical Statistics 27, 1075-1090.

Silverman, B.W., 1998. Density Estimation for Statistics and Data Analysis. London: Chapman \& Hall/CRC. p. 48.

Williams, B., 2014. Bank risk and national governance in Asia. Journal of Banking and Finance 49, 10-26. 
Figure 1. Graphical presentation of the Z-score with different left-skewed probability density functions.

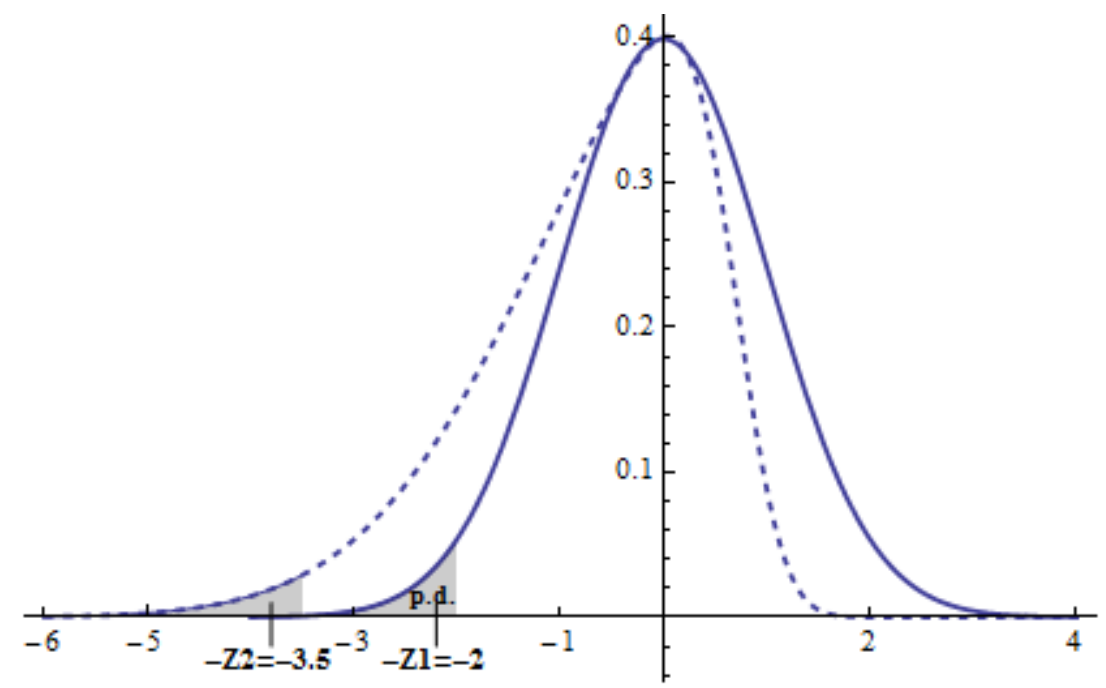

Notes: This figure depict the graphical presentation of the Z-score with left-skewed (dashed line) and Gaussian (continued line) probability density functions for the $R O A$. Shaded part, p.d., represents the probability of default, $\operatorname{Pr}[R O A \leq-C A R]=N(-\mathrm{Z})$. Z1 is the Z-score of a normal distribution and $\mathrm{Z} 2$ is the Z-score of a leftskewed distribution. 
Figure 2. Distribution fit with different sharpness of the probability density function and with different skewnesses.

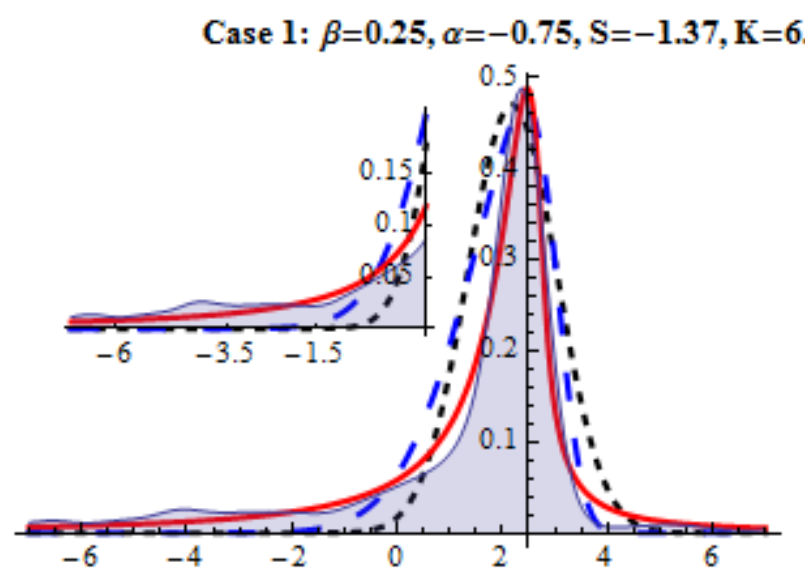

Case 4: $\beta=1.25, \alpha=-0.75, \mathrm{~S}=-2.14, \mathrm{~K}=11.91$
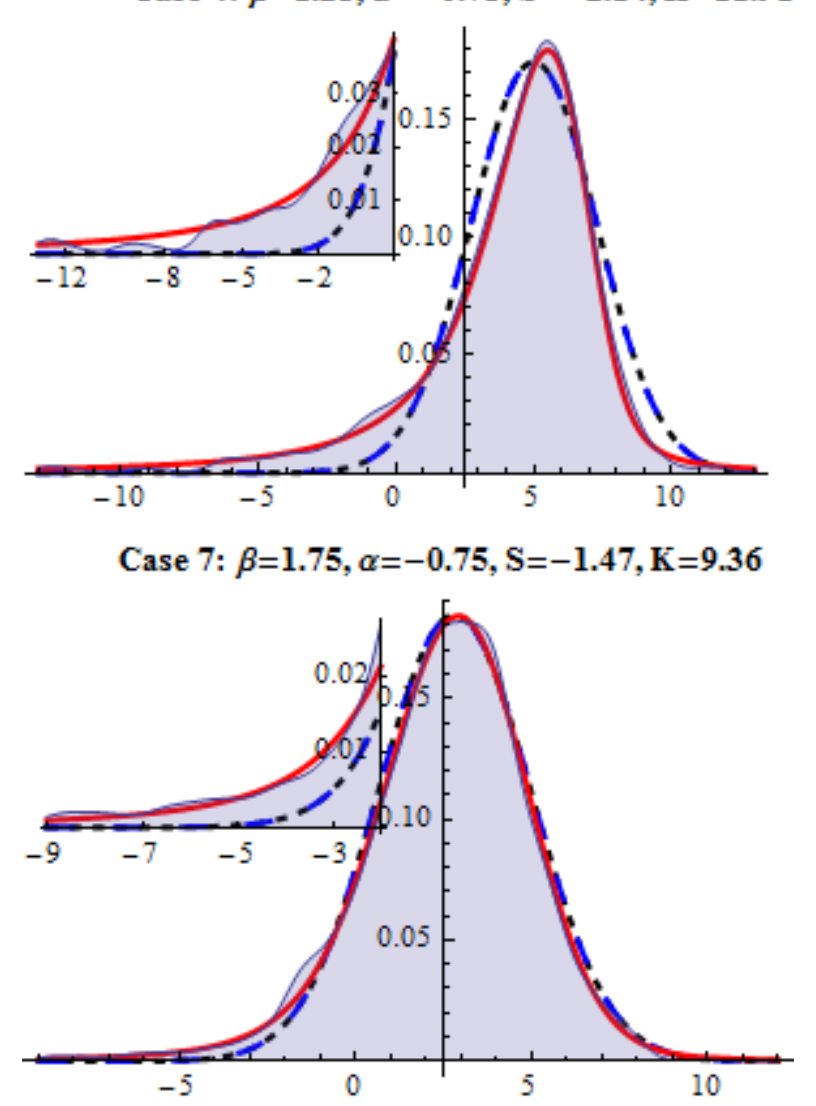

Case 2: $\beta=0.25, \alpha=0, \mathrm{~S}=-0.85, \mathrm{~K}=8.64$

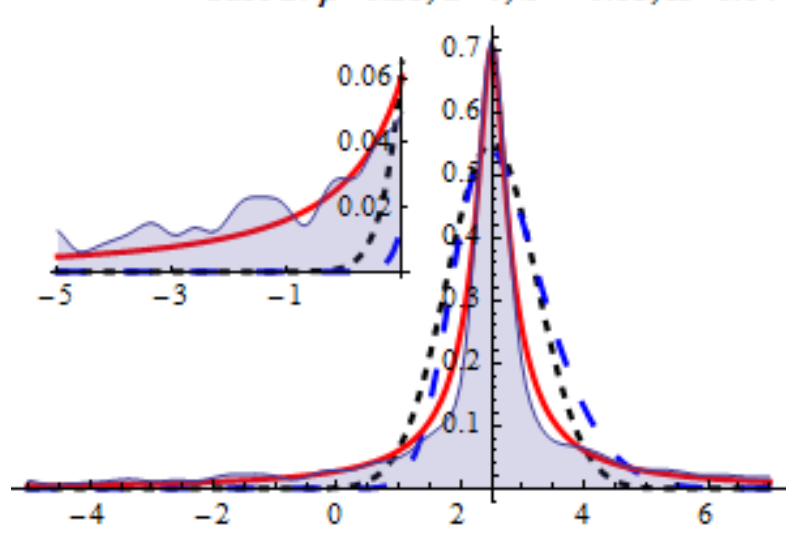

Case 5: $\beta=1.25, \alpha=0, \mathrm{~S}=-0.49, \mathrm{~K}=9.66$
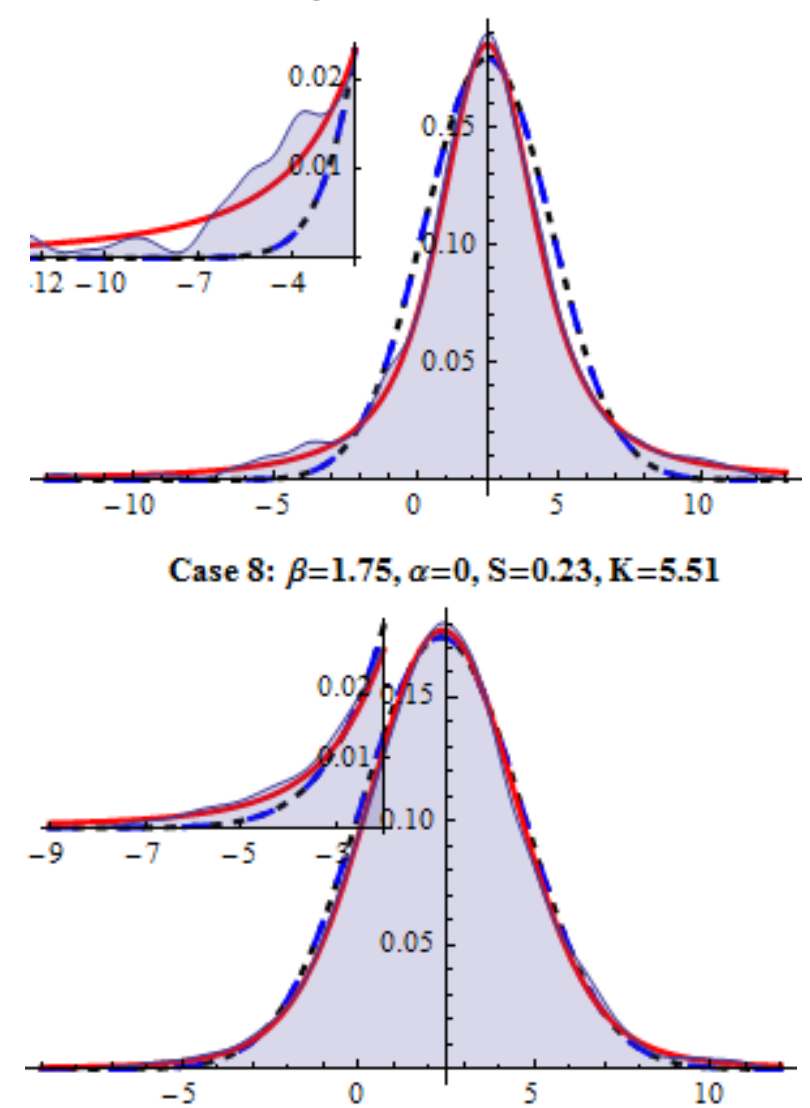

Case 3: $\beta=0.25, \alpha=0.75, \mathrm{~S}=0.68, \mathrm{~K}=7.82$

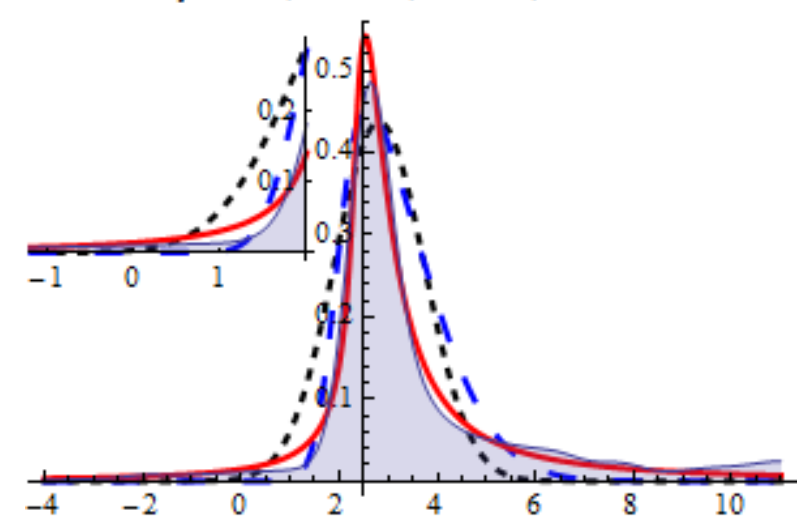

Case 6: $\beta=1.25, \alpha=0.75, \mathrm{~S}=1.75, \mathrm{~K}=7.79$

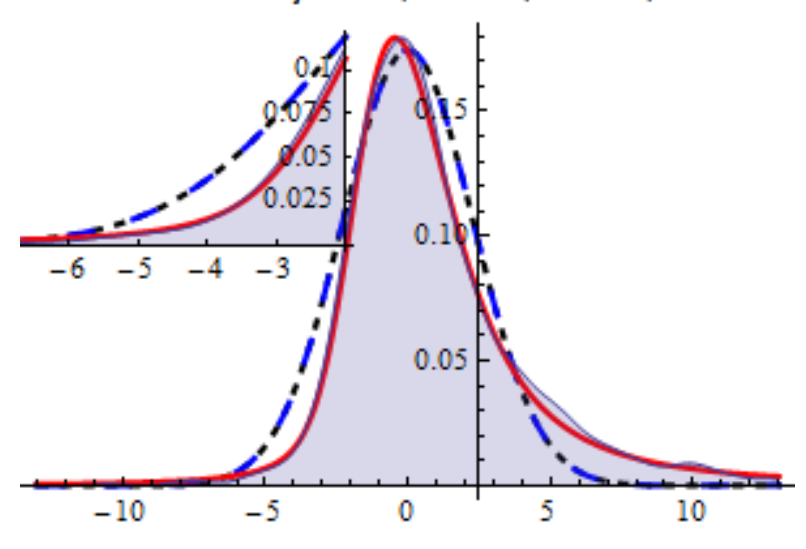

Case 9: $\beta=1.75, \alpha=0.75, \mathrm{~S}=1.04, \mathrm{~K}=7.10$

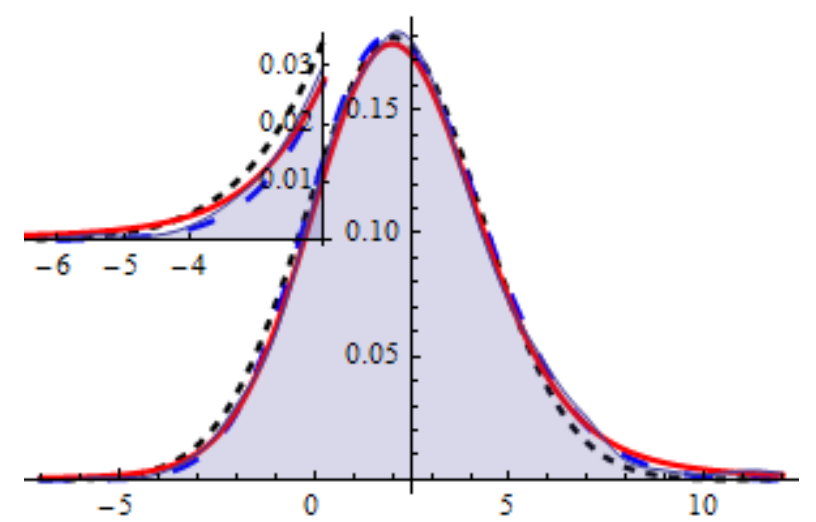

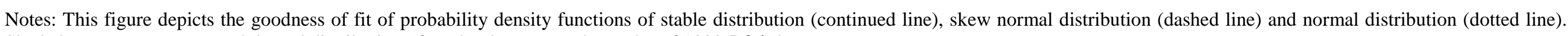
Shaded area represents smooth kernel distribution of randomly generated samples of 1000 ROA data. 
Figure 3. Test of equality between traditional and stable distribution estimates

For Z-score

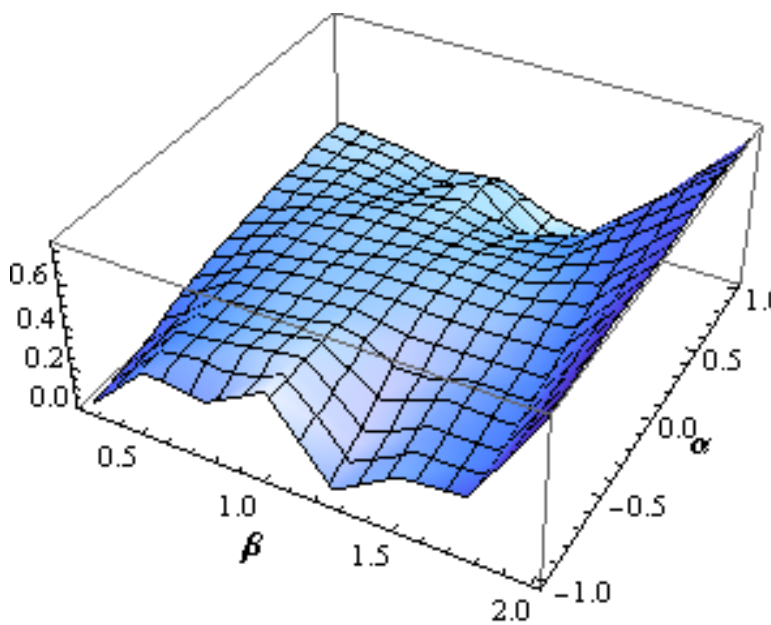

For $\operatorname{Ln}(1+\mathrm{Z})$

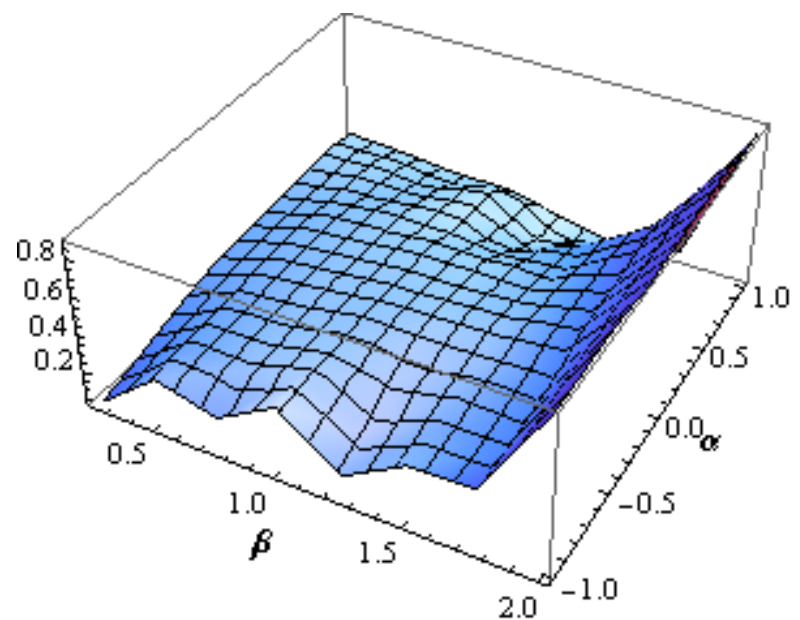

Figure 4. Test of equality between traditional and skew normal distribution estimates.

For Z-score

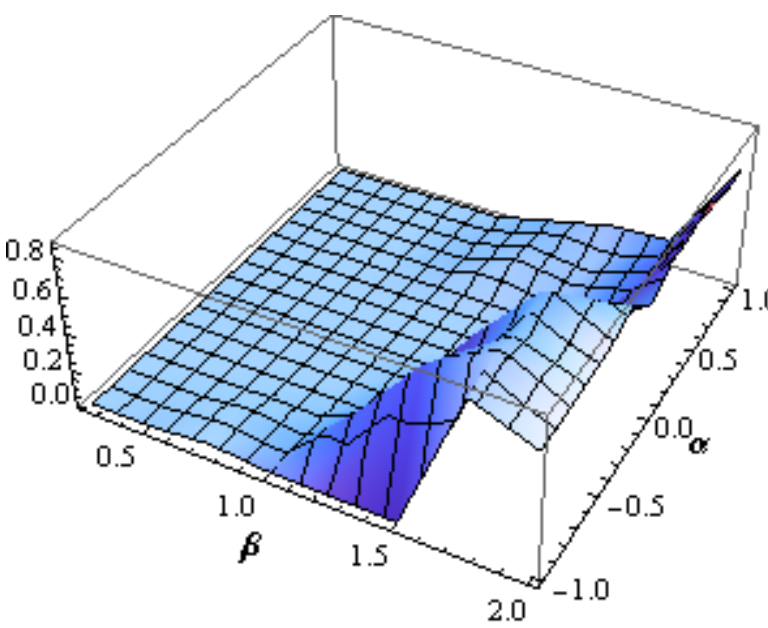

For $\operatorname{Ln}(1+\mathrm{Z})$

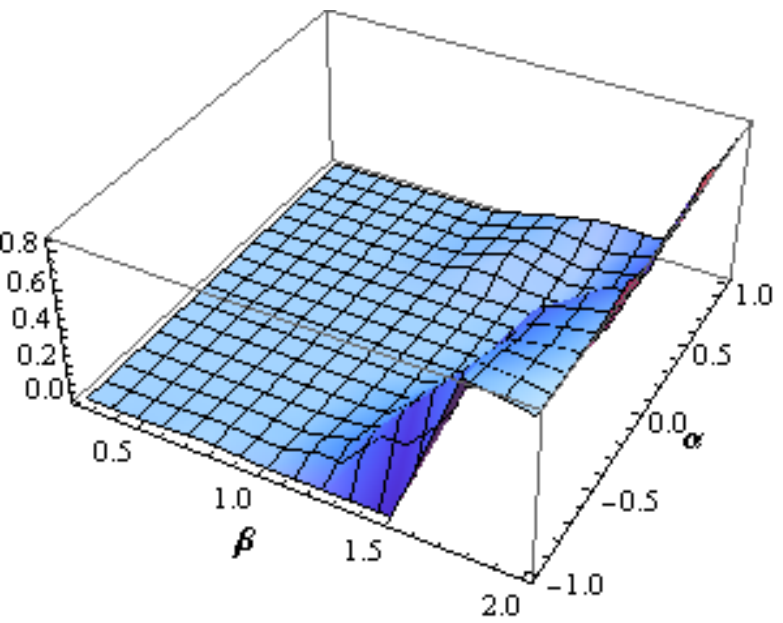

Figure 5. Test of equality between traditional and normal distribution estimates.

For Z-score

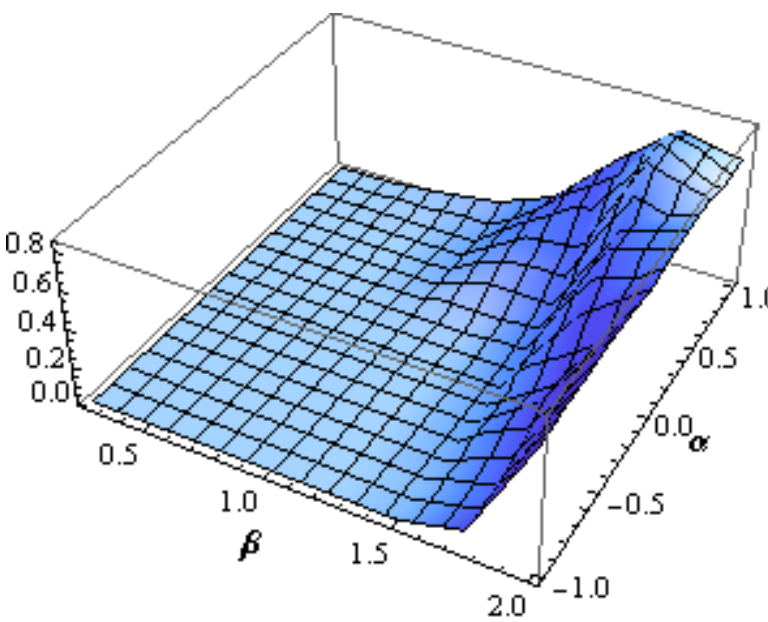

For $\operatorname{Ln}(1+Z)$

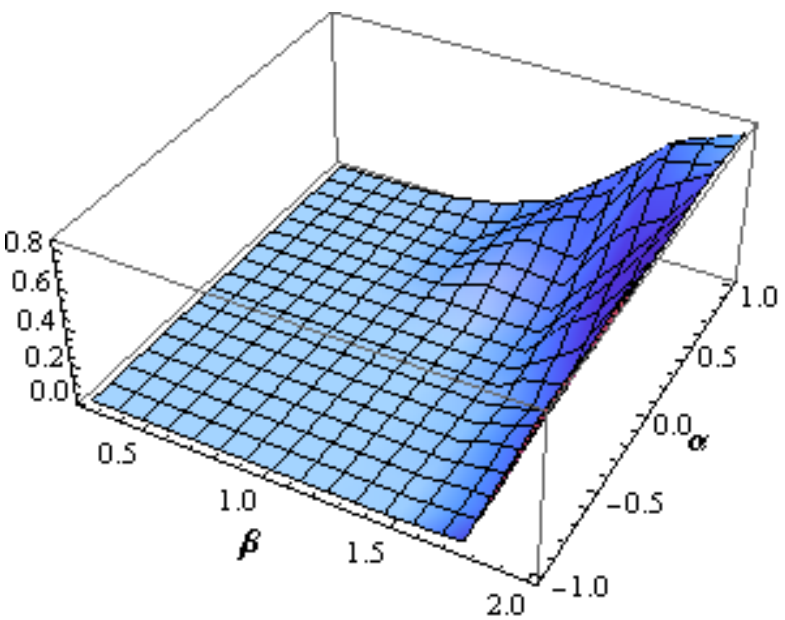


Table 1. Summary of empirical studies in the banking literature applying the Z-score.

\begin{tabular}{|c|c|c|c|c|}
\hline Authors & r.v. & $\begin{array}{l}\text { Mean } \\
\text { value }\end{array}$ & $\begin{array}{l}\text { Presence of r.v. in } \\
\text { the Z-score formula }\end{array}$ & Estimation method \\
\hline $\begin{array}{l}\text { Demirgüç-Kunt and } \\
\text { Huizinga (2010) }\end{array}$ & $R O A$ & 30.74 & $\begin{array}{l}\text { In average on entire } \\
\text { sample }\end{array}$ & Traditional \\
\hline $\begin{array}{l}\text { Laeven and Levine } \\
\text { (2009) }\end{array}$ & $R O A$ & 17.81 & $\begin{array}{l}\text { In average on entire } \\
\text { sample }\end{array}$ & Traditional and the use of $\operatorname{Ln}(\mathrm{Z})$. \\
\hline $\begin{array}{l}\text { Demirgüç-Kunt et } \\
\text { al. (2008) }\end{array}$ & $R O A$ & - & $\begin{array}{l}\text { In average on entire } \\
\text { sample }\end{array}$ & Traditional and the use of $\operatorname{Ln}(1+Z)$. \\
\hline $\begin{array}{l}\text { Anginer et al. } \\
\text { (2014) }\end{array}$ & $R O A$ & 33.12 & $\begin{array}{l}\text { In average on } 5 \text { years } \\
\text { rolling window }\end{array}$ & $\begin{array}{l}\text { Yearly Z-score with average of } R O A \text { and } \\
C O A \text { divided on standard deviation of } \\
R O A \text {, with } 5 \text { years rolling window. The } \\
\text { use of } \operatorname{Ln}(\mathrm{Z}) \text {. }\end{array}$ \\
\hline Williams (2014) & $R O A$ & $\begin{array}{l}-0.22 \\
(-0.10)\end{array}$ & $\begin{array}{l}\text { In } 2 \text { and } 4 \text { years } \\
\text { average rolling window }\end{array}$ & $\begin{array}{l}\text { Yearly Z-score with average of } R O A \text { and } \\
\text { average of }-C O A \text { divided on standard } \\
\text { deviation of } R O A \text {, with } 2 \text { (4) years } \\
\text { rolling window. }\end{array}$ \\
\hline Anolli et al. (2014) & $R O A$ & $\begin{array}{l}103- \\
129\end{array}$ & In 4 quarters average & $\begin{array}{l}\text { Yearly Z-score with } 4 \text { quarters average } \\
\text { and standard deviation of } R O A \text { and } 4 \\
\text { quarters average of } C O A \text {. }\end{array}$ \\
\hline $\begin{array}{l}\text { De Haan and } \\
\text { Poghosyan (2012) }\end{array}$ & $\begin{array}{l}R O A \text { and } \\
R O E\end{array}$ & $\begin{array}{c}261 \\
(185)\end{array}$ & $\begin{array}{l}\text { In } 4 \text { and } 8 \text { quarters } \\
\text { average }\end{array}$ & $\begin{array}{l}\text { Yearly Z-score with } 4 \text { (8) quarters } \\
\text { average and standard deviation of } R O A \\
(R O E) \text { and } 4 \text { (8) quarters average of } \\
C O A \text {. }\end{array}$ \\
\hline $\begin{array}{l}\text { Lee and Hsieh } \\
(2014)\end{array}$ & $\begin{array}{l}R O A \text { and } \\
R O E\end{array}$ & $\begin{array}{c}52 \\
(12)\end{array}$ & In level & $\begin{array}{l}\text { Yearly } R O A(R O E) \text { and } C O A \text { in levels } \\
\text { and standard deviation on } 3 \text { years rolling } \\
\text { window. }\end{array}$ \\
\hline $\begin{array}{l}\text { Chortareas et al. } \\
\text { (2012) }\end{array}$ & $R O A$ & 8.91 & In level & $\begin{array}{l}\text { Yearly } R O A(R O E) \text { and } C O A \text { in levels } \\
\text { and standard deviation on } 5 \text { years rolling } \\
\text { window. }\end{array}$ \\
\hline Niu (2012) & $R O A$ & 7.95 & In level & $\begin{array}{l}\text { Yearly } R O A \text { and } C O A \text { in levels and } \\
\text { standard deviation on entire year sample. }\end{array}$ \\
\hline $\begin{array}{l}\text { Fiordelisi and Mare } \\
\text { (2014) }\end{array}$ & $R O A$ & 17.25 & In level & $\begin{array}{l}\text { Yearly } R O A \text { and } C O A \text { in levels and } \\
\text { yearly standard deviation within each } \\
\text { individual country. }\end{array}$ \\
\hline
\end{tabular}

Notes: This table provides summary of empirical studies in the banking literature applying the Z-score as an accounting-based bank risk measure and presents the main methods in estimating the Z-score. r.v. signifies random variable. 
Table 2. Parameters of $R O A$ distribution laws.

\begin{tabular}{|c|c|c|c|c|c|c|c|c|c|}
\hline Distribution & Case 1 & Case 2 & Case 3 & Case 4 & Case 5 & Case 6 & Case 7 & Case 8 & Case 9 \\
\hline \multicolumn{10}{|l|}{ Stable Distr. } \\
\hline$\mu$ & -0.041 & 2.289 & 2.895 & 3.784 & 2.359 & 1.381 & 2.552 & 2.634 & 2.381 \\
\hline$\sigma$ & 1.625 & 0.993 & 0.932 & 1.838 & 1.580 & 1.674 & 1.510 & 1.636 & 1.531 \\
\hline$\alpha$ & -0.644 & 0.051 & 0.442 & -0.410 & 0.049 & 0.529 & 0.340 & 0.360 & 0.146 \\
\hline$\beta$ & 1.194 & 0.952 & 1.045 & 1.453 & 1.510 & 1.398 & 1.754 & 1.715 & 1.700 \\
\hline \multicolumn{10}{|c|}{ Skew Normal Distr. } \\
\hline$\mu$ & 2.056 & 2.433 & 2.614 & 5.492 & 2.227 & -0.248 & 2.931 & 2.356 & 2.508 \\
\hline$\sigma$ & 2.594 & 1.568 & 1.655 & 2.985 & 2.434 & 2.569 & 2.434 & 2.639 & 2.416 \\
\hline$\alpha$ & -1.242 & 0.311 & 1.305 & -0.680 & 0.148 & 0.370 & -0.194 & 0.191 & 0.063 \\
\hline \multicolumn{10}{|l|}{ Normal Distr. } \\
\hline$\mu$ & 1.716 & 2.517 & 3.006 & 4.986 & 2.391 & -0.019 & 2.655 & 2.498 & 2.536 \\
\hline$\sigma$ & 2.207 & 1.347 & 1.32 & 2.629 & 2.239 & 2.376 & 2.154 & 2.356 & 2.208 \\
\hline
\end{tabular}

Notes: This table provides estimates of parameters of ROA distribution laws, i.e. stable, skew normal and normal distributions. The nine cases correspond to three different sharpness of the distribution shape $(\beta=0.25, \beta=1.25$ and $\beta=1.75)$, each of them with three different skewnesses $(\alpha=-0.75, \alpha=0$ and $\alpha=0.75)$. 
Table 3. Number of rejections on fifty tests that verify the conformity of estimated distribution with generated ROA series.

\begin{tabular}{cccccccccc}
\hline Distribution & Case 1 & Case 2 & Case 3 & Case 4 & Case 5 & Case 6 & Case 7 & Case 8 & Case 9 \\
\hline Stable Distr. & 0 & 3 & 2 & 0 & 0 & 0 & 0 & 0 \\
AD & 0 & 2 & 1 & 0 & 0 & 0 & 0 & 0 \\
CVM & 8 & 2 & 4 & 0 & 0 & 0 & 0 & 0
\end{tabular}

Skew Normal Distr.

$\begin{array}{cccccccccc}\text { AD } & 40 & 45 & 44 & 5 & 10 & 13 & 0 & 0 \\ \text { CVM } & 4 & 3 & 3 & 0 & 0 & 0 & 0 & 0 & 0 \\ \text { KS } & 25 & 3 & 16 & 0 & 0 & 0 & 0 & 0 & 0\end{array}$

Normal Distr.

\begin{tabular}{|c|c|c|c|c|c|c|c|c|c|}
\hline$A D$ & 42 & 45 & 46 & 10 & 9 & 13 & 0 & 0 & 0 \\
\hline CVM & 11 & 2 & 7 & 0 & 0 & 0 & 0 & 0 & 0 \\
\hline KS & 28 & 5 & 15 & 0 & 0 & 0 & 0 & 0 & 0 \\
\hline
\end{tabular}

Notes: This table presents the results of conformity tests of estimated distributions, i.e. stable, skew normal and normal distributions, with randomly generated ROA series. The nine cases correspond to three different sharpness of the distribution shape $(\beta=0.25, \beta=1.25$ and $\beta=1.75)$, each of them with three different skewnesses $(\alpha=-0.75, \alpha=0$ and $\alpha=0.75$ ). For each case, fifty samples are randomly generated and three distribution fit tests, at $5 \%$ significance level, are considered, i.e. Anderson-Darling test (AD),

Cramer-von-Mises test (CvM) and Kolmogorov-Smirnov test (KS). 
Table 4. Number of fitted tests rejections on total number of estimates.

\begin{tabular}{|c|c|c|c|c|c|c|c|c|c|c|}
\hline & Bulgaria & Czech Rp. & Hungary & Estonia & Latvia & Lithuania & Poland & Romania & Slovakia & Slovenia \\
\hline \multicolumn{11}{|l|}{ StD } \\
\hline CvM & $0 / 23$ & $0 / 20$ & $0 / 21$ & $0 / 6$ & $0 / 22$ & $0 / 9$ & $0 / 37$ & $0 / 25$ & $0 / 16$ & $0 / 14$ \\
\hline \multicolumn{11}{|l|}{ SkND } \\
\hline$A D$ & $9 / 23$ & $3 / 20$ & $5 / 21$ & $1 / 6$ & $7 / 22$ & $3 / 9$ & $4 / 37$ & $4 / 25$ & $7 / 16$ & $5 / 14$ \\
\hline CvM & $0 / 23$ & $1 / 20$ & $0 / 21$ & $0 / 6$ & $0 / 22$ & $0 / 9$ & $0 / 37$ & $0 / 25$ & $0 / 16$ & $0 / 14$ \\
\hline \multicolumn{11}{|l|}{$N D$} \\
\hline$A D$ & $8 / 23$ & $4 / 20$ & $5 / 21$ & $3 / 6$ & $11 / 22$ & $5 / 9$ & $7 / 37$ & $6 / 25$ & $9 / 16$ & $8 / 14$ \\
\hline CVM & $0 / 23$ & $0 / 20$ & $0 / 21$ & $0 / 6$ & $0 / 22$ & $0 / 9$ & $1 / 37$ & $0 / 25$ & $0 / 16$ & $0 / 14$ \\
\hline KS & $0 / 23$ & $0 / 20$ & $0 / 21$ & $0 / 6$ & $0 / 22$ & $0 / 9$ & $1 / 37$ & $0 / 25$ & $0 / 16$ & $0 / 14$ \\
\hline
\end{tabular}

Notes: This table presents the results of conformity tests of estimated distributions, i.e. Stable Distribution (StD), Skew Normal Distribution (SkND) and Normal Distribution (ND), for CEE banks' ROA. For each of ten countries, three distribution fit tests are considered, i.e. Anderson-Darling test (AD), Cramer-von-Mises test (CvM) and Kolmogorov-Smirnov test (KS), and the results indicate how many banks on entire bank sample do not conform to the estimated distributions according to their $R O A$ distribution, at 5\% significance level. 
Table 5. Estimates of Z-score measures for CEE countries.

\begin{tabular}{|c|c|c|c|c|c|c|c|c|c|c|c|c|c|c|c|c|c|c|c|}
\hline Risk measure & 1995 & 1996 & 1997 & 1998 & 1999 & 2000 & 2001 & 2002 & 2003 & 2004 & 2005 & 2006 & 2007 & 2008 & 2009 & 2010 & 2011 & 2012 & 2013 \\
\hline \multicolumn{20}{|l|}{ Bulgaria } \\
\hline Zscore1 & 2.60 & 3.00 & 3.13 & 4.38 & 4.42 & 5.74 & 5.80 & 4.58 & 4.63 & 4.33 & 4.21 & 4.04 & 3.70 & 4.58 & 5.24 & 4.52 & 4.07 & 4.17 & 4.18 \\
\hline Zscore2 & 11.05 & 17.51 & 15.31 & 16.54 & 16.10 & 19.10 & 15.62 & 13.80 & 12.71 & 11.92 & 10.91 & 9.87 & 9.31 & 11.03 & 12.21 & 11.39 & 10.99 & 11.49 & 11.69 \\
\hline Zscore3 & 13.60 & 23.02 & 18.30 & 21.05 & 20.00 & 24.03 & 19.01 & 16.57 & 14.79 & 13.71 & 12.36 & 10.72 & 10.04 & 12.39 & 13.96 & 12.89 & 12.32 & 13.06 & 13.34 \\
\hline Zscore4 & 4.75 & 6.34 & 4.53 & 9.54 & 9.80 & 13.19 & 10.42 & 8.39 & 8.43 & 8.03 & 7.23 & 6.71 & 6.57 & 8.75 & 9.87 & 8.76 & 7.87 & 8.14 & 8.56 \\
\hline \multicolumn{20}{|l|}{ Czech Rep. } \\
\hline Zscore1 & 2.45 & 2.63 & 2.52 & 2.45 & 4.07 & 4.90 & 4.67 & 4.75 & 3.81 & 3.67 & 3.74 & 3.90 & 3.73 & 4.35 & 4.82 & 5.30 & 5.48 & 5.86 & 5.45 \\
\hline Zscore2 & 10.46 & 24.66 & 15.58 & 17.86 & 16.27 & 14.01 & 14.76 & 14.11 & 13.74 & 13.95 & 14.29 & 13.54 & 12.23 & 12.80 & 13.75 & 14.70 & 14.35 & 14.87 & 14.53 \\
\hline Zscore3 & 14.49 & 31.91 & 18.95 & 20.82 & 18.75 & 16.74 & 17.79 & 17.73 & 17.31 & 17.86 & 18.40 & 17.34 & 15.71 & 15.99 & 16.87 & 18.28 & 17.94 & 18.24 & 17.75 \\
\hline Zscore4 & 10.75 & 21.47 & 12.53 & 14.28 & 13.71 & 12.60 & 12.29 & 11.66 & 11.87 & 12.44 & 12.84 & 12.20 & 10.78 & 11.08 & 12.29 & 13.34 & 13.33 & 13.55 & 12.88 \\
\hline \multicolumn{20}{|l|}{ Estonia } \\
\hline Zscore1 & 2.68 & 2.50 & 2.13 & 2.36 & 2.38 & 2.37 & 2.39 & 2.36 & 2.35 & 2.36 & 2.28 & 2.31 & 2.28 & 2.26 & 2.13 & 2.18 & 2.17 & 2.29 & 2.22 \\
\hline Zscore2 & 13.67 & 11.04 & 6.19 & 9.75 & 10.33 & 9.14 & 8.96 & 8.93 & 8.98 & 9.30 & 8.42 & 7.89 & 7.57 & 7.74 & 6.89 & 7.90 & 9.24 & 10.57 & 10.91 \\
\hline Zscore3 & 17.57 & 14.79 & 8.02 & 13.31 & 13.91 & 11.94 & 11.62 & 12.26 & 12.61 & 13.71 & 12.35 & 11.07 & 10.41 & 9.89 & 8.95 & 10.41 & 12.31 & 14.26 & 14.49 \\
\hline Zscore4 & 9.25 & 7.65 & 3.77 & 6.27 & 6.75 & 5.95 & 5.86 & 7.45 & 7.85 & 8.15 & 6.95 & 6.52 & 5.96 & 5.48 & 4.75 & 5.50 & 6.13 & 7.20 & 7.21 \\
\hline \multicolumn{20}{|l|}{ Latvia } \\
\hline Zscore1 & 3.16 & 2.94 & 5.47 & 5.62 & 5.24 & 3.98 & 3.39 & 3.30 & 2.92 & 3.20 & 3.78 & 3.57 & 3.09 & 3.16 & 3.42 & 2.93 & 3.52 & 4.11 & 4.04 \\
\hline Zscore2 & 55.70 & 10.93 & 12.08 & 11.43 & 9.77 & 7.87 & 9.81 & 7.78 & 7.93 & 7.23 & 8.17 & 7.31 & 7.37 & 7.51 & 7.06 & 6.64 & 7.46 & 8.97 & 9.03 \\
\hline Zscore3 & 55.64 & 11.73 & 13.43 & 12.74 & 10.90 & 8.32 & 12.13 & 8.88 & 9.16 & 7.95 & 8.78 & 8.12 & 7.98 & 8.12 & 8.13 & 7.45 & 8.42 & 10.09 & 9.96 \\
\hline Zscore4 & 19.20 & 5.35 & 8.08 & 8.12 & 7.14 & 5.02 & 7.96 & 5.04 & 5.40 & 4.77 & 5.26 & 4.85 & 4.77 & 5.06 & 5.08 & 4.25 & 4.77 & 5.87 & 6.30 \\
\hline \multicolumn{20}{|l|}{ Lithuania } \\
\hline Zscore1 & 2.31 & 2.51 & 2.46 & 2.68 & 2.73 & 2.60 & 2.51 & 2.49 & 2.47 & 2.38 & 2.36 & 2.36 & 2.38 & 2.40 & 2.39 & 2.24 & 2.40 & 2.45 & 2.44 \\
\hline Zscore2 & 11.04 & 17.52 & 15.34 & 19.68 & 20.60 & 17.23 & 14.52 & 13.38 & 12.59 & 10.46 & 10.33 & 9.34 & 10.19 & 11.51 & 10.78 & 9.87 & 11.10 & 12.52 & 11.58 \\
\hline Zscore3 & 10.89 & 22.65 & 19.84 & 26.51 & 26.93 & 22.19 & 19.03 & 17.76 & 16.83 & 13.98 & 13.27 & 11.70 & 12.66 & 14.72 & 13.77 & 12.59 & 14.36 & 16.18 & 15.19 \\
\hline Zscore4 & 9.21 & 11.61 & 8.43 & 13.29 & 13.59 & 10.40 & 8.57 & 7.72 & 7.41 & 6.02 & 5.36 & 4.90 & 5.22 & 5.98 & 5.80 & 5.21 & 5.13 & 5.81 & 5.56 \\
\hline
\end{tabular}


Table 5. Estimates of Z-score measures for CEE countries (continued).

\begin{tabular}{|c|c|c|c|c|c|c|c|c|c|c|c|c|c|c|c|c|c|c|c|}
\hline Risk measure & 1995 & 1996 & 1997 & 1998 & 1999 & 2000 & 2001 & 2002 & 2003 & 2004 & 2005 & 2006 & 2007 & 2008 & 2009 & 2010 & 2011 & 2012 & 2013 \\
\hline \multicolumn{20}{|l|}{ Hungary } \\
\hline Zscore1 & 3.17 & 3.12 & 3.36 & 3.12 & 3.06 & 3.09 & 3.18 & 3.21 & 3.20 & 3.15 & 3.17 & 3.14 & 3.10 & 3.04 & 3.14 & 3.04 & 2.98 & 3.09 & 3.20 \\
\hline Zscore2 & 9.80 & 9.42 & 9.97 & 10.81 & 10.51 & 11.07 & 10.67 & 10.38 & 9.63 & 9.84 & 9.75 & 13.60 & 10.20 & 9.39 & 10.10 & 10.20 & 9.41 & 9.80 & 9.81 \\
\hline Zscore3 & 11.19 & 10.71 & 11.28 & 11.62 & 11.06 & 12.04 & 11.82 & 11.54 & 10.50 & 11.24 & 10.88 & 16.73 & 11.36 & 10.36 & 11.44 & 11.74 & 10.75 & 11.41 & 11.51 \\
\hline Zscore4 & 8.95 & 8.41 & 9.44 & 9.01 & 8.52 & 9.17 & 9.20 & 8.70 & 8.19 & 9.00 & 8.59 & 10.28 & 8.65 & 8.07 & 9.02 & 9.39 & 8.95 & 9.52 & 9.78 \\
\hline \multicolumn{20}{|l|}{ Poland } \\
\hline Zscore1 & 2.97 & 2.97 & 2.97 & 3.00 & 2.98 & 3.07 & 3.04 & 3.06 & 2.92 & 2.97 & 2.96 & 2.96 & 2.96 & 2.91 & 2.96 & 2.96 & 2.96 & 3.00 & 3.03 \\
\hline Zscore2 & 13.00 & 13.35 & 13.86 & 13.89 & 13.45 & 17.95 & 13.39 & 12.84 & 11.95 & 11.81 & 11.15 & 11.81 & 11.47 & 10.75 & 11.14 & 11.62 & 11.57 & 12.36 & 12.43 \\
\hline Zscore3 & 16.11 & 16.49 & 16.92 & 16.71 & 15.90 & 20.83 & 15.61 & 15.19 & 14.08 & 13.62 & 12.70 & 13.58 & 12.87 & 11.81 & 12.67 & 13.17 & 13.01 & 14.11 & 14.18 \\
\hline Zscore4 & 13.03 & 11.92 & 12.07 & 12.04 & 10.83 & 15.34 & 11.91 & 11.95 & 10.86 & 10.84 & 10.43 & 11.07 & 10.47 & 9.45 & 10.34 & 10.67 & 10.63 & 11.62 & 12.29 \\
\hline \multicolumn{20}{|l|}{ Romania } \\
\hline Zscore1 & 2.57 & 2.81 & 2.58 & 3.69 & 3.64 & 3.59 & 3.56 & 3.60 & 3.40 & 3.20 & 3.54 & 3.50 & 3.18 & 3.34 & 3.25 & 3.32 & 3.32 & 3.30 & 3.31 \\
\hline Zscore2 & 9.29 & 16.96 & 9.50 & 11.42 & 10.25 & 11.30 & 10.07 & 9.36 & 8.66 & 8.12 & 7.70 & 7.66 & 7.08 & 7.21 & 6.60 & 7.11 & 7.40 & 7.21 & 7.04 \\
\hline Zscore3 & 10.62 & 19.91 & 10.57 & 14.22 & 12.24 & 13.56 & 11.79 & 10.90 & 9.95 & 9.07 & 8.78 & 8.85 & 8.08 & 8.19 & 7.53 & 8.14 & 8.62 & 8.45 & 8.21 \\
\hline Zscore4 & 6.63 & 7.48 & 4.86 & 8.29 & 7.12 & 8.26 & 7.36 & 6.95 & 6.31 & 6.00 & 6.00 & 5.66 & 4.91 & 5.22 & 4.94 & 5.40 & 5.65 & 5.29 & 5.26 \\
\hline \multicolumn{20}{|l|}{ Slovakia } \\
\hline Zscore1 & 2.59 & 2.55 & 2.64 & 2.58 & 2.54 & 2.65 & 2.65 & 2.69 & 2.71 & 2.69 & 2.66 & 2.64 & 2.64 & 2.61 & 2.58 & 2.54 & 2.64 & 2.66 & 2.64 \\
\hline Zscore2 & 15.65 & 14.04 & 13.89 & 15.87 & 16.45 & 19.01 & 15.05 & 15.01 & 16.38 & 15.37 & 14.66 & 14.56 & 14.70 & 14.31 & 15.80 & 15.11 & 16.36 & 17.31 & 16.50 \\
\hline Zscore3 & 21.72 & 16.34 & 16.50 & 19.74 & 21.39 & 23.67 & 18.58 & 18.63 & 20.23 & 18.85 & 17.98 & 18.17 & 18.21 & 17.67 & 20.00 & 19.08 & 20.90 & 22.33 & 21.79 \\
\hline Zscore4 & 10.38 & 7.71 & 8.70 & 9.64 & 9.96 & 10.62 & 9.32 & 10.02 & 11.17 & 10.56 & 9.95 & 9.58 & 9.43 & 8.89 & 9.48 & 9.26 & 10.25 & 10.89 & 10.38 \\
\hline \multicolumn{20}{|l|}{ Slovenia } \\
\hline Zscore1 & 4.71 & 3.64 & 3.60 & 3.78 & 3.71 & 3.63 & 3.53 & 3.46 & 3.42 & 3.43 & 3.24 & 3.31 & 3.21 & 3.17 & 3.26 & 3.34 & 3.35 & 3.32 & 3.24 \\
\hline Zscore2 & 13.26 & 10.82 & 24.09 & 21.21 & 20.31 & 18.60 & 16.03 & 13.09 & 12.14 & 11.70 & 11.84 & 10.91 & 10.13 & 9.76 & 10.32 & 9.93 & 9.71 & 9.39 & 9.25 \\
\hline Zscore3 & 19.72 & 14.62 & 27.17 & 24.16 & 23.06 & 21.26 & 18.45 & 15.35 & 14.20 & 13.70 & 13.67 & 12.71 & 12.07 & 11.67 & 12.22 & 11.97 & 11.92 & 11.50 & 11.41 \\
\hline Zscore4 & 8.76 & 6.51 & 17.85 & 15.77 & 15.04 & 13.66 & 11.54 & 9.00 & 8.01 & 7.57 & 7.64 & 7.01 & 6.06 & 5.73 & 6.34 & 6.09 & 6.11 & 6.12 & 6.26 \\
\hline
\end{tabular}

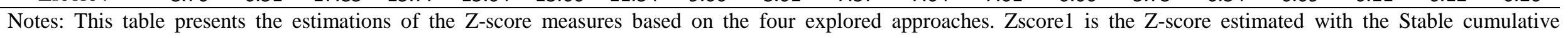

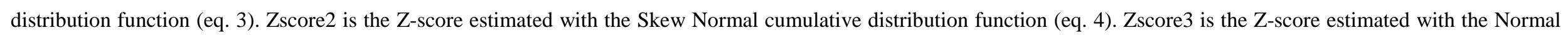
cumulative distribution function (eq. 5). Zscore4 is the Z-score estimated with the traditional approach (eq. 6). 


\section{RECENT LAREFI WORKING PAPERS}

\section{For earlier LAREFI Working Papers, please go to http://lare-efi.u-bordeaux4.fr}

\section{All Discussion Papers can be downloaded free of charge}

CR16-EFI04 Lapteacru, I., "Income and funding structures, banking regulation and bank risk-taking : The role of ownership in Central and Eastern European banks"

CR16-EFI03 Humblot, T., "Distance et accès au crédit sous Bâle III"

CR16-EFI02 Berthoumieu, J. and V. Lamani, "Vertical Differentiation, Uncertainty, Product R\&D and Policy Instruments in a North-South Duopoly"

CR16-EFI01 Raffestin, L., "Foreign exchange investment rules and endogenous currency crashes" CR15-EFI05 Berthoumieu,J., "Technology Diffusion via Patent Collaborations : The Case of European Integration"

CR15-EFI04 Bouet, A. and A-G. Vaubourg, "Financial Constraints and International Trade with Endogenous Mode of Competition"

CR15-EFI03 Lahet, D. and A-G. Vaubourg, "Banks' shareholding in multilateral trading facilities : A two-sided market perspective"

CR15-EFI02 Berthoumieu, J., "Policy Instruments, Patents and International Technology Diffusion in a North-South Duopoly"

CR15-EFI01 Dupuy, L., "International trade and structural change : a dynamic model of weak sustainability"

CR14-EFI06 Humblot, T., "Basel III and SMEs' access to bank credit : An empirical assessment"

CR14-EFI05 Nicet-Chenaf, D., Rougier, E., "Source and host country volatility and FDI : A gravity analysis of European investment to Middle East and North Africa"

CR14-EFI/04 Djigbenou, M-L., "Determinants of Global Liquidity Dynamics:a FAVAR approach"

CR14-EFI/03 Vaubourg, A-G., "Finance and international trade : A review of the literature"

CR14-EFI/02 Sangaré, I., "Chocs extérieurs et régimes monétaires en Asie du Sud-Est : une analyse DSGE"

CR14-EFI/01 Lacoue-Labarthe, D., "In Search of the Banking Regulator amid U.S. Financial Reforms of the 1930s" 